\title{
Analyzing research article introductions by Iranian and native English-speaking authors of Applied Linguistics
}

Shahriari Ahmadi, Hesamoddin

Ferdowsi University of Mashhad, Iran (hesamshahriari@yahoo.com)

Ghonsooly, Behzad

Ferdowsi University of Mashhad, Iran (ghonsooly@yahoo.com)

Hosseini Fatemi, Azar

Ferdowsi University of Mashhad, Iran (azar.h.fatemi@gmail.com)

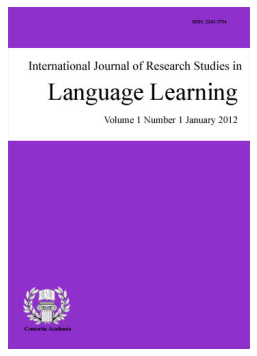

ISSN: 2243-7754 Online ISSN: 2243-7762

OPEN ACCESS

\section{Abstract}

Considering the role of academic writing in the dissemination of research findings among members of scientific communities, efforts have been made by language specialists to achieve a more detailed understanding of this register, with hopes that the derived features could then be used to teach researchers, writing in a second/foreign language, to more effectively communicate the results of their studies. This study sets out to achieve a similar goal through the analysis of research article introductions in terms of the frequency and function of their lexical bundles. To this end, a corpus of 200 research article introductions by published authors in the field of Applied Linguistics was compared to a similar corpus by Iranian, non-native writers of the same field. The findings reveal that Iranian authors use more 4-word lexical bundles in their writing compared to their native-speaker counterparts. Syntactic and functional differences between the two corpora are introduced and implications for academic writing instructors are discussed in detail.

Keywords: lexical bundles; multiword expressions; corpus linguistics; research articles 


\section{Analyzing research article introductions by Iranian and native English-speaking authors of Applied Linguistics}

\section{Introduction}

Academic writing registers, especially the research article, have become the subject of numerous ESP studies. This trend could be attributed to the value placed upon publishing research results and sharing one's findings with the academic community. In addition, in many countries, graduate students are also expected to publish their work in international journals, meaning they have to develop advanced writing skills in their own field of specialty. In Iran, English is the language of communication for some designated university majors; this particularly holds true for the field of English language studies. In Iranian universities, English is the predominant language used in textbooks, classroom lectures and discussions for students of English, in general, and Applied Linguistics in particular. University entrance exams include general language proficiency items, which guarantee the admission of those students who are more advanced in terms of their general English language proficiency. However, despite the advanced level of communicative skills in English, students are still found struggling when it comes to assignments involving academic writing. This comes as no surprise, since even native speakers require formal training in order to gain the ability to write academic research articles.

Assuming there is a continuum of proficiency in academic writing, where fully-competent writers of research articles stand at one extreme, it would be highly useful to locate where advanced learners are currently placed along the continuum and what are the gaps which need to be bridged for them to achieve more efficient writing skills. This is a delicate task, because differences between the writing of such advanced level students and the norms established within the register cannot be labeled as mistakes or errors, and should rather be referred to as deviations from the norm. Such deviations are very difficult to single out relying only on one's intuition. This is where corpus linguistics methods can be of substantial help to the researcher. Instead of relying on intuitions regarding the nature of language, the corpus-based approach to linguistic analysis draws heavily upon empirical data to answer language-related questions. The applications of corpus-based research are numerous, which is why an increasingly greater number of researchers are adopting corpus tools for answering their research questions. Besides their applications in materials development (Flowerdew, 1996), language corpora have been used to improve various aspects of writing such as knowledge of grammar (Diniz \& Moran, 2005), genre awareness (Tribble, 2002) and vocabulary knowledge (Nation, 2001; Altenberg, 1998).

\subsection{The corpus-driven approach to academic writing}

Corpus-driven methodologies can be used to analyze and identify the most frequent or infrequent features within learner language (i.e., common grammatical structures, lexis, and discourse items), comparing them with the standard norms within the register, with the purpose of improving the quality of pedagogy and materials development. Most studies in this area have set their sights on describing the linguistic features of academic research articles. While some have focused on providing a thorough description of language used in a particular scientific field (e.g., Halliday, 1988), others have attempted to compare and contrast features of academic language with that of other genres (e.g., Biber, Johansson, Leech, Conrad, \& Finegan, 1999). There have also been a series of studies directed towards investigating the various aspects of academic language as produced by learners. For instance, there have been several studies aimed at comparing academic language by foreign/second language learners with that of their native-speaker counterparts (Granger, 1998). In fact, a number of large-scale learner corpora have been compiled and are extensively used for the above-mentioned purposes. Leech (1998) maintains that a collection of learner texts representing learner language is a valuable resource to teachers and researchers wishing to gain a better understanding of how languages are learned and how the learning process can be improved. 
Analyzing research article introductions by Iranian and native English-speaking authors of Applied Linguistics

Almost all of the established learner corpora in the field exclusively include written academic language. This could either be attributed to the importance of academic writing as a register or to the relative ease with which such corpora can be compiled, as compared to spoken registers. The most well-known learner corpora currently used in the field also vary depending on the background of the learners from whom texts are collected. While some corpora include learner texts from a variety of language backgrounds, others limit themselves to a particular learner group (e.g., Cantonese, Polish or Hungarian speakers). Each of these two categories of learner corpora can be used to provide answers to different types of research questions, depending on their specificity. Variations can also be seen in terms of the proficiency level of the target learners and the genres and styles included into the corpus (e.g., argumentative essays, exam texts, etc.). Some of the most widely-recognized learner corpora include the International Corpus of Learner English (ICLE), the Upsala Student English corpus (USE), the Cambridge Learner Corpus (CLC), and the Longman Learners' Corpus (LLC), just to name a few.

\subsection{Expert writing vs. non-native writing}

A corpus comparison between academic writing by advanced, non-native writers and professional authors writing within the same register can help define the existing differences between the two. These qualitative differences in language use can then serve multiple purposes. First, they can be used to create awareness among advanced learners regarding the existing gaps in their writing proficiency. In other words, it would serve to inform them of what changes could be made to their already-advanced writing skills in order to bring it closer to what is standard among the members of the academic writing discourse community. Second, the findings of such a study would be of great value to writing instructors who are preparing graduate students for writing publishable research articles. If such instruction were based on empirical evidence found in large corpora, in contrast to intuitive speculations regarding the norms of academic writing, it would most probably result in more successful writers and greater ease in publishing.

\subsection{Lexical bundles}

One linguistic unit which has become the subject of numerous comparative corpus studies in recent years is the lexical bundle. Biber and Conrad (1999) define lexical bundles as a sequence of words which recur with a relatively high frequency within a register. Lexical bundles are different from idioms in that they are non-compositional, semantically transparent and occur far more frequently in discourse. In addition, they are not always structurally complete. Lexical bundles are also commonly found in great numbers in academic registers. For example, although most words within a text do not occur in recurrent combinations, around $21 \%$ of the academic sub-corpus of the Longman corpus of Spoken and Written English appear in frequent bundles, some seen over 200 times per million words. When extracting lexical bundles from a corpus, a purely frequency-based approach is adopted (Altenberg, 1998; Butler, 1997; Biber et al., 1999). Therefore; the size of the bundle can affect the probability of its occurrence. For example, a 4-word bundle can be expected to be found less frequently than a 3 -word bundle.

\subsection{Categories of lexical bundles}

Lexical bundles have been categorized both structurally and functionally. The most widely-used structural analysis of bundles has been proposed by Biber et al. (1999) who categorizes bundles into three types: independent verb fragments, verb fragments with dependent clause elements and noun phrase fragments. The first type includes verb fragments, beginning with a subject pronoun followed by a verb phrase. This type of bundle could also begin with a verb phrase, without a pronoun or question fragment. Bundles beginning with discourse markers followed by a verb phrase and question fragments are also categorized under this category. The second type of bundle characterized by verb phrase elements incorporating dependent clause fragments often include a complementizer followed by a main clause or a WH-word presenting a dependent clause. Dependent clause fragments starting with a complementizer or subordinator also form Type 2 bundles. The third categories mainly include noun phrase components ending in a post-modifier, prepositional phrase component 
Shahriari Ahmadi, H., Ghonsooly, B., \& Hosseini Fatemi, A.

with modifiers or involve comparative expressions.

\subsection{Previous comparisons between expert and non-native writing}

Multiple studies have attempted to compare learner- and native-speaker corpora based on their frequency and type of lexical bundles. Cortes (2002) compared the use of lexical bundles by university students and published authors in the disciplines of history and biology. The results of her study revealed that students used fewer lexical bundles compared to professional writers, and there was very little overlap between the bundles used by the two groups. Baker and Chen (2010) made use of an automated frequency-driven method to draw a comparison between lexical bundles in published academic texts and student academic writing. This findings of this study also showed that learners use a comparatively narrower range of lexical bundles, but occasionally overuse specific lexical sequences that are rarely encountered in the corpus of texts by professional academic writers. In another study, Wei and Lei (2011) looked at lexical bundles across a corpus of doctoral dissertations by advanced Chinese EFL writers and published research articles by professional writers. Contrary to the previous two studies, the authors found that advanced learners used more frequent bundles and with a greater range. Generally, studies on lexical bundles have found differences between native and non-native language users both in terms of the frequency of bundles (Erman, 2009; Howarth, 1998; Adel \& Erman, 2012) and in terms of the variety and range of bundles (Granger, 1998; Lewis, 2009).

\subsection{Significance of the study}

Previous studies in the area have looked at lexical bundles in research articles or dissertations as a whole. To our understanding, no study has looked into the use of lexical bundles in a particular sub-section of a register (except for the abstract, which is often seen as a separate genre in itself). The advantage of such an attempt is that through limiting the discourse functions of the texts, we can hope to extract more specific bundles, which consequently allow for more controlled comparisons. We also believe that the more limited range of functions in a specific section would lead to greater accuracy in the discoursal classification of bundles. In addition, the authors of the present study share the opinion that the highly technical nature of academic writing calls for a more detailed analysis. In other words, it would be simplistic to presuppose that all sections of the research article are similar in terms of their language features and style. A separate analysis of each section, however, would result in a more detailed understanding of the language used, and would consequently be of greater use to advanced learners. The present study compares Applied Linguistics research article introductions and literature reviews by professional writers for whom English is a native language and their Iranian non-native speaker counterparts with regards to the frequency and type of lexical bundles. The results of the analysis will hopefully inform the process of writing pedagogy as well as presenting a clear profile of academic writing in research article introductions in Applied Linguistics.

\section{Method}

\subsection{The corpus}

For this study, a 768,242-word corpus consisting of 400 research article introductions and literature reviews was compiled. From the 400 selected articles, 200 were authored by native speakers of English (NS), and published in accredited Applied Linguistics journals, namely Applied Linguistics, TESOL Quarterly, English for Specific Purposes and Journal of Second Language Writing. The remaining 200 articles were written by Iranian authors (IA) who had published their work in well-known Applied Linguistics journals inside Iran; these journals were Journal of Teaching Language Skills, Iranian Journal of Applied Linguistics, Iranian Journal of Applied Language Studies and Research in Foreign Languages. Each of the journals mentioned above contributed an equal number of articles (50) to the corpus. The NS sub-corpus consisted of 340,814 word tokens and 15,946 word types (The type-token ratio for this sub-corpus was 0.04), while the INNS corpus of introductions and 
Analyzing research article introductions by Iranian and native English-speaking authors of Applied Linguistics

literature reviews consisted of 427,428 word tokens and 20,016 word types (The type-token ratio for this sub-corpus was also 0.04). All articles were randomly selected from different issues of the selected journals. Details of the compiled corpus have been presented in Table 1 below:

\section{Table 1}

Details of sub-corpora used in the analysis

\begin{tabular}{lclc}
\hline \multicolumn{1}{c}{ Journals } & (NS) & \multicolumn{1}{c}{ Journals } & (INNS) \\
\hline Applied Linguistics & 50 & Journal of Teaching Language Skills & 50 \\
TESOL Quarterly & 50 & Iranian Journal of Applied Linguistics & 50 \\
ESP Journal & 50 & Iranian Journal of Applied Language Studies & 50 \\
Journal of Second Language Writing & 50 & Research in Foreign Languages & 50 \\
\hline
\end{tabular}

\subsection{Procedure}

The corpus was searched for existing lexical bundles. In this study, we have adopted Biber et al.'s (1999) definition of lexical bundles, in which these units are defined as the most recurrent multi-word sequences within a particular register. This analysis was completed through a customized computer program written by the authors. The size of lexical bundles often varies across studies depending on the research purpose and other logistical elements such as the availability of units and their use in teaching and/or analysis. The present study focused on 4-word lexical bundles. The rationale behind this choice was that 4-word sequences appear more frequently than 3-word bundles and exhibit more clear structures compared to bi-grams or two word sequences (Hyland, 2008). Another decision in studies of lexical bundles is the frequency cut-off point for identification. In this study, sequences had to appear at least 5 times within the corpus to be considered as a recurring unit. Most studies tend to norm the counts so that the used corpora would be comparable. However, since the two corpora used in this study incorporated an equal number of texts (200), there was no need for norming. This decision ultimately leads to more identified bundles which are directly in line with the exploratory aims of the researchers. To avoid idiosyncratic expressions used by individual authors, another restriction was enforced, in which attestations for a given sequence would have to have occurred in at least 5 different texts.

Lexical bundles are known to not always represent complete structural units. Instead, they often serve to link two clausal or phrasal elements to each other. The relatively high frequency with which these bundles occur within a passage attests to their important role in language production and makes up for their lack of syntactic and semantic wholeness. In fact, by looking at lexical bundles, we can arrive at an index representing the degree to which the formulaic principle is prominent in the authors' use of language.

\section{Results and discussion}

The analysis of the two corpora resulted in a series of 4-word lexical bundles. The NS and INNS corpora contained 88 and 153 bundles, respectively. The most frequently recurring bundle in both corpora was on the other hand, which occurred 132 times in the INNS corpus and 66 times in the NS corpus. In general, among the ten most frequent bundles of each corpus, five were shared by both groups of writers. These included on the other hand, in the field of, in the context of, the extent to which and at the same time. The bundle in the field of ranked second in terms of frequency in the INNS corpus (with 64 attestations). The same bundle was the fifth most recurring bundle in the NS corpus, with 41 occurrences. The fourth most common bundle in each of the two corpora was in the context of, having been found 50 times in the INNS corpus and 46 times in the NS corpus. The extent to which was the third most common bundle used by native speakers (with 57 instances found in the NS corpus) and ranked sixth among the most recurring bundles in the INNS corpus (with 46 attestations). Finally, at the same time ranked ninth in both the NS and INNS corpora, with 37 and 40 attestations, respectively. Overall, 63 bundles were discovered to be shared by both groups of authors. These included bundles such as English as a second, as a foreign language and of English as a, which constitute chunks of characteristic phrases 
Shahriari Ahmadi, H., Ghonsooly, B., \& Hosseini Fatemi, A.

in the field of Applied Linguistics (e.g., of English as a second language). Tables 2 and 3 below show the list of 4-word lexical bundles along with their frequency in the NS and INNS corpora, respectively. The lexical bundles common between the two corpora have been presented in bold.

Table 2

Most frequent 4-word lexical bundles found in the NS sub-corpus

\begin{tabular}{|c|c|c|c|c|c|}
\hline Bundles & $\mathrm{F}$ & Bundles & $\mathrm{F}$ & Bundles & $\mathrm{F}$ \\
\hline On the other hand & 66 & In the form of & 20 & The present study is & 13 \\
\hline The use of English & 59 & In terms of their & 20 & Of English for Specific & 12 \\
\hline The extent to which & 57 & The use of the & 20 & Use of English as & 12 \\
\hline In the context of & 46 & The context of the & 18 & An important role in & 12 \\
\hline In the field of & 41 & In the process of & 18 & As a foreign language & 12 \\
\hline English for specific purposes & 41 & At the university of & 18 & From the perspective of & 12 \\
\hline As well as the & 37 & A number of studies & 18 & In the area of & 12 \\
\hline In the present study & 37 & To be able to & 17 & To the development of & 12 \\
\hline At the same time & 37 & In the target language & 17 & Are more likely to & 11 \\
\hline The nature of the & 31 & In the United States & 17 & Extent to which the & 11 \\
\hline It is important to & 31 & Can be seen as & 16 & Is based on the & 11 \\
\hline Native speakers of English & 29 & Can be used to & 16 & Of the English language & 11 \\
\hline Of English as a & 28 & As a result of & 15 & Studies have been conducted & 11 \\
\hline On the use of & 27 & At the level of & 15 & To refer to the & 11 \\
\hline As a second language & 27 & Extent to which the & 15 & In the light of & 11 \\
\hline In the case of & 27 & Of this study is & 15 & It is necessary to & 11 \\
\hline Of the present study & 26 & To the use of & 15 & An understanding of the & 10 \\
\hline The ways in which & 25 & The role of the & 15 & As a way of & 10 \\
\hline That the use of & 24 & English as a second & 14 & In a number of & 10 \\
\hline A wide range of & 24 & In a variety of & 14 & In the use of & 10 \\
\hline In terms of the & 24 & Number of studies have & 14 & Language teaching and learning & 10 \\
\hline On the one hand & 23 & Through the use of & 14 & Research in this area & 10 \\
\hline Use of English in & 22 & There has been a & 14 & The development of the & 10 \\
\hline The purpose of the & 22 & The following research questions & 14 & The meaning of the & 10 \\
\hline The degree to which & 21 & In the sense that & 13 & The relationship between the & 10 \\
\hline One of the most & 21 & The importance of the & 13 & The results showed that & 10 \\
\hline On the basis of & 21 & That there is a & 13 & The use of a & 10 \\
\hline English for academic purposes & 21 & In relation to the & 13 & This study is to & 10 \\
\hline The results of the & 21 & The structure of the & 13 & Within the context of & 10 \\
\hline
\end{tabular}

The bundles extracted from the two corpora were classified both in terms of their structure and their function. The structural categorization of bundles in this study followed the taxonomy introduced by Biber et al. (1999). The majority of bundles found in both corpora were phrasal, which is typical of the academic genre. The NS and INNS corpora had $74(83.1 \%)$ and 116 (75.8\%) phrasal bundles, respectively. After phrasal bundles, verbal phrase fragments were the second most common type of bundles found in both groups of research article introductions and literature reviews. The NS corpus contained $11(12.3 \%)$ such bundles and the INNS corpus included $29(18.9 \%)$. Finally, the verb phrase element followed by a dependent clause was least found in both groups of texts. The NS and INNS corpora included 4 (4.4\%) and 8 (5.2\%) subordinate verb phrase elements, respectively. Figure 1 below illustrates the distribution of different types of bundles in the NS and INNS corpora. 
Analyzing research article introductions by Iranian and native English-speaking authors of Applied Linguistics

Table 3

Most frequent 4-word lexical bundles found in the INNS sub-corpus

\begin{tabular}{|c|c|c|c|c|c|}
\hline Bundles & $\mathrm{F}$ & Bundles & $\mathrm{F}$ & Bundles & $\mathrm{F}$ \\
\hline On the other hand & 132 & In the target language & 18 & Of the fact that & 13 \\
\hline In the field of & 64 & Investigated the effect of & 18 & Studies have been conducted & 13 \\
\hline On the basis of & 50 & Native speakers of English & 18 & The development of a & 13 \\
\hline In the context of & 50 & Of the most important & 18 & Through the use of & 13 \\
\hline One of the most & 49 & On the use of & 18 & Learning a second language & 13 \\
\hline The extent to which & 46 & To be able to & 18 & The use of the & 13 \\
\hline As a foreign language & 46 & With respect to the & 18 & For the purpose of & 13 \\
\hline As a result of & 42 & It is possible to & 17 & It is important to & 13 \\
\hline At the same time & 40 & The present study was & 17 & A significant relationship between & 12 \\
\hline English as a foreign & 42 & That there is no & 17 & Be considered as a & 12 \\
\hline As well as the & 38 & English as a second & 17 & As a means of & 12 \\
\hline Is one of the & 36 & In second language learning & 17 & At the level of & 12 \\
\hline In the form of & 36 & In the area of & 16 & Can be used as & 12 \\
\hline The following research questions & 35 & The fact that the & 16 & Extent to which the & 12 \\
\hline On the one hand & 33 & Learning a foreign language & 16 & In a foreign language & 12 \\
\hline In the process of & 32 & Is concerned with the & 16 & In a way that & 12 \\
\hline In the case of & 30 & Of the use of & 16 & In the second language & 12 \\
\hline On the part of & 28 & On the relationship between & 16 & Is based on the & 12 \\
\hline The nature of the & 28 & A great deal of & 16 & Is referred to as & 12 \\
\hline In the use of & 27 & Can be used to & 15 & Is there a significant & 12 \\
\hline In the present study & 26 & In a number of & 15 & Number of studies have & 12 \\
\hline That there is a & 26 & In a variety of & 15 & Of the study have & 12 \\
\hline The degree to which & 26 & The basis of the & 15 & Of the study were & 12 \\
\hline The results of the & 24 & Learning English as a & 15 & Should be noted that & 12 \\
\hline A change of state & 24 & The importance of the & 15 & Significant difference between the & 12 \\
\hline In terms of the & 23 & This study is to & 15 & That the use of & 12 \\
\hline In terms of their & 22 & It is necessary to & 15 & The field of language & 12 \\
\hline Of the target language & 22 & Is there any significant & 15 & To find out the & 12 \\
\hline Of this study is & 22 & It should be noted & 15 & Of language teaching and & 12 \\
\hline The present study is & 22 & The ways in which & 15 & Field of second language & 12 \\
\hline To the fact that & 22 & Results of the study & 15 & There has been a & 12 \\
\hline Of the present study & 22 & The results showed that & 15 & For the first time & 11 \\
\hline The purpose of the & 21 & The field of second & 15 & Of Iranian EFL learners & 11 \\
\hline Language teaching and learning & 21 & Investigated the relationship between & 14 & Of this study was & 11 \\
\hline With regard to the & 21 & Language learning and teaching & 14 & On the role of & 11 \\
\hline Of English as a & 21 & Answers to the following & 14 & In the United States & 11 \\
\hline The relationship between the & 21 & At the end of & 14 & Studies have focused on & 11 \\
\hline The role of the & 21 & On the nature of & 14 & The content of the & 11 \\
\hline A wide range of & 20 & Purpose of this study & 14 & The last two decades & 11 \\
\hline Is an attempt to & 20 & Studies have been carried & 14 & There is no significant & 11 \\
\hline Second or foreign language & 20 & Study is an attempt & 14 & Were found to be & 11 \\
\hline The Iranian EFL learners & 20 & The end of the & 14 & Important role in the & 10 \\
\hline
\end{tabular}


Shahriari Ahmadi, H., Ghonsooly, B., \& Hosseini Fatemi, A.

Table 3 ... continue

Most frequent 4-word lexical bundles found in the INNS sub-corpus

\begin{tabular}{ll|ll|l}
\hline \multicolumn{1}{c|}{ Bundles } & F & \multicolumn{1}{|c|}{ Bundles } & F & \multicolumn{1}{c}{ Bundles } \\
\hline A large number of & 20 & The language of the & 14 & Degree to which the \\
An important role in & 19 & The part of the & 14 & Findings of this study \\
Beliefs about language learning & 19 & The process of learning & 14 & In the sense that \\
Have been carried out & 19 & As a second language & 14 & Is likely to be \\
Is there any relationship & 19 & In the study of & 14 & Is related to the \\
In an attempt to & 19 & The results indicated that & 13 & Of the nature of \\
The purpose of this & 19 & And the use of & 13 & The relationship between language \\
Of teaching and learning & 19 & Can be considered as & 10 & This study was to \\
There any relationship between & 19 & In a second language & 13 & 10 \\
As one of the & 18 & In second language acquisition & 13 & 10 \\
\hline
\end{tabular}

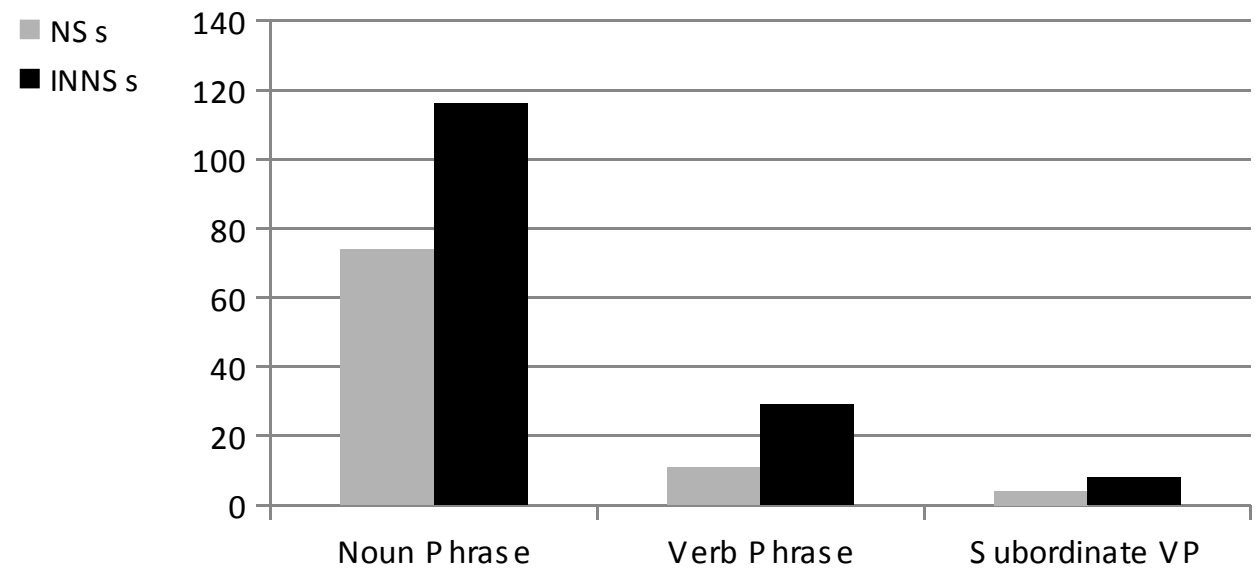

Figure 1. Distribution of noun phrase, verbal phrase and subordinate verbal phrase bundles in the NS and INNS corpora

A functional analysis involves the classification of lexical bundles into distinct categories based on the discourse purposes they serve in texts. The present study followed a top-down approach to the analysis of discourse functions (Biber, Connor, \& Upton, 2007). Through such an approach, identified bundles are categorized into distinct discourse categories based on a specific analytical framework. Two analytical frameworks were used in this study. One was the taxonomy developed by Cortes (2002) and later improved by Biber et al. (2007). The second was the revised genre prototype developed by Swales (2004).

In the first framework, three major functional types are introduced: Stance Bundles, Discourse Organizers and Referential Expressions. Stance Bundles refer to that group of bundles which reveal the attitude of the writer or judgments regarding the degree of certainty, proposition or ability. Bundles belonging to the group of Discourse Organizers serve to structure and organize the text by clarifying or elaborating on the topic. The third, category of lexical bundles, Referential Expressions, reference physical or abstract entities or the textual context itself. It is possible for a specific lexical bundle to express different functions. The table below provides a more detailed description of the taxonomy used in this study.

The lexical bundles were initially categorized based on the first analytical framework. As expected from written academic registers, the most prevalent type of bundle in both corpora was Referential Expressions (with 73 and 119 instances in the NS and INNS corpora, respectively). Discourse Organizers were the second most common type of bundle (with 8 and 24 instances in the NS and INNS corpora, respectively). Finally, the least 
Analyzing research article introductions by Iranian and native English-speaking authors of Applied Linguistics common functional category of lexical bundles, based on the first framework, was Stance Expressions (with 7 and 10 instances in the NS and INNS corpora, respectively). Table 5 shows the number and percentage of different types of lexical bundles classified according to the first analytical framework.

\section{Table 4}

Functional classification of lexical bundles

Lexical Bundle Category Example

\section{Stance Expressions}

a. Epistemic Stance

Personal

Impersonal

b. Attitudinal/Modality Stance

b.1. Desire

b.2. Obligation/Directive

Personal

Impersonal

b.3. Intention/Prediction

Personal

Impersonal

b.4. Ability

Personal

Impersonal
I don't know if

Are more likely to

I don't want to

You might want to

It is important to

What we're going to

Are going to be

To be able to

Can be used to

\section{Discourse Organizers}

a. Topic Introduction/Focus

Let's have a look

b. Topic Elaboration/Clarification

On the other hand

\section{Referential Expressions}

a. Identification/ Focus

One of the most

b. Imprecision

Or something like that

c. Specification of Attributes
c.1. Quantity Specification
The rest of the
c.2. Tangible Framing Attribute
In the form of
c.3. Intangible Framing Attribute
The nature of the

d. Time/Place/Text Reference
d.1. Place Reference
In the United States
d.2. Time Reference
At the time of
d.3. Text Deixis
As shown in figure

e. Research Reference Bundles

The following research questions

f. Subject-Specific Bundles

English for Specific Purposes

According to the second discourse analytical framework, research article introductions as a genre are divided into three major moves: Establishing a territory, establishing a niche and presenting the present work. Each of these three steps, in turn, consists of a number of moves. An outline of the proposed moves and steps is presented in table 5 below. 
Shahriari Ahmadi, H., Ghonsooly, B., \& Hosseini Fatemi, A.

\section{Table 5}

Swales' revised genre prototype for research article introductions (2004, pp. 230, 232)

\begin{tabular}{ll}
\hline Move 1: & Establishing a territory (citations required) via Topic generalizations of increasing specificity \\
\hline Move 2: & Establishing a niche (citations required) via: \\
& Step 1A: indicating a gap, or \\
& Step 1B: Adding to what is known \\
& Step 2: Presenting positive justification (optional) \\
\hline Move 3 & Presenting the present work via: \\
& Step 1: Announcing the present research descriptively and/or purposively (obligatory) \\
& Step 2: Presenting research questions or hypotheses* (optional) \\
& Step 3: Definitional clarifications* (optional) \\
& Step 4: Summarizing methods* (optional) \\
& Step 5: Announcing principal outcomes (optional)** \\
& Step 6: Stating the value of the present research (optional)** \\
& Step 7: Outlining the structure of the paper (optional)** \\
\hline Notes: * Steps 2-4 are less fixed in their order of occurrence than the others. ** Steps 5-7 are probable in some fields, but unlikely in others.
\end{tabular}

\section{Table 6}

Number and Percentage of lexical bundles according to the first analytical framework

Lexical Bundle Category $\quad$ NS - Number NS - Percentage INNS-Number INNS $(\%)$

\section{Stance Expressions}

a. Epistemic Stance

$\begin{array}{lllll}\text { Personal } & 0 & 0.00 \% & 0 & 0.00 \% \\ \text { Impersonal } & 0 & 0.00 \% & 1 & 0.65 \%\end{array}$

b. Attitudinal/Modality Stance
b.1. Desire
0
$0.00 \%$
0
$0.00 \%$

b.2. Obligation/Directive

$\begin{array}{lllll}\text { Personal } & 0 & 0.00 \% & 0 & 0.00 \% \\ \text { Impersonal } & 3 & 3.40 \% & 7 & 4.57 \%\end{array}$

b.3. Intention/Prediction

$\begin{array}{lcccc}\text { Personal } & 0 & 0.00 \% & 0 & 0.00 \% \\ \text { Impersonal } & 1 & 1.13 \% & 0 & 0.00 \% \\ \text { Ability } & & & & \\ \text { Personal } & 0 & 0.00 \% & 0 & 0.00 \% \\ \text { Impersonal } & 3 & 3.40 \% & 2 & 1.30 \%\end{array}$

\section{Discourse Organizers}

a. Topic Introduction/Focus

4

$4.54 \%$


Analyzing research article introductions by Iranian and native English-speaking authors of Applied Linguistics

Table 6 ... continue

Number and Percentage of lexical bundles according to the first analytical framework

\begin{tabular}{lllll}
\hline Lexical Bundle Category & NS - Number & NS - Percentage & INNS-Number & INNS (\%) \\
\hline
\end{tabular}

\section{Referential Expressions}

$\begin{array}{lcccc}\text { a. Identification/ Focus } & 3 & 3.40 \% & 5 & \mathbf{3 . 2 6 \%} \\ \text { b. Imprecision } & 0 & 0.00 \% & 0 & 0.00 \% \\ \begin{array}{l}\text { c. Specification of Attributes } \\ \text { c.1. Quantity Specification }\end{array} & & & & \\ \quad \text { c.2. Tangible Framing Attribute } & 0 & 2.27 \% & 4 & 2.61 \% \\ \quad \text { c.3. Intangible Framing Attribute } & 44 & 0.00 \% & 0 & 0.00 \% \\ \text { d. Time/Place/Text Reference } & & 50.00 \% & 58 & 37.90 \% \\ \quad \text { d.1. Place Reference } & 4 & & & \\ \quad \text { d.2. Time Reference } & 1 & 4.54 \% & 1 & 0.65 \% \\ \quad \text { d.3. Text Deixis } & 0 & 1.13 \% & 3 & 1.92 \% \\ \text { e. Research Reference Bundles } & 7 & 0.00 \% & 0 & 0.00 \% \\ \text { f. Subject-Specific Bundles } & 12 & 7.95 \% & 18 & 11.76 \%\end{array}$

As can be seen in Table 5, considering the percentage of bundles related to each of the three functions, it appears that native-speakers made use of a greater proportion of lexical bundles for describing their attitudes and assessments and also reflecting the relationship between prior and coming discourse. On the other hand, Iranian non-native speakers used a larger fraction of their bundles for referencing purposes. It is also interesting to note that Iranian authors used relatively more subject-related and research-referencing bundles in their writing. Subject-related bundles refer to those 4-word sequences that referenced a concept or notion specific to the field of Applied Linguistics. Some examples of such bundles are:

... English by Brazilians and in English by native speakers of English (NS Corpus)

... that deserve investigation in language teaching and learning circles are fear of... (INNS Corpus)

On the other hand, research-related bundles were those expressions which made reference to the study itself or other reports of research. These bundles were sometimes difficult to identify, because by just looking at the lexical bundle itself, one could not always tell whether the expression was referencing a research study or any of its elements. Therefore, the KWIC (Key Word in Context) tool was used whenever references were not clear. Below are two examples of research-related expressions from the NS and INNS corpora.

The value of the present study lies in providing better information about (NS Corpus)

To achieve this purpose, the following research questions were addressed (INNS Corpus)

The decision to include a second framework in the functional analysis of lexical bundles came from the need to classify bundles according to genre-specific criteria. That is, the functional taxonomy provided by Biber et al. (2007) is a general one that can be used to classify lexical bundles coming from texts of different registers. By using Swales' (2004) genre prototype for article introductions, we hope to achieve a more genre-specific classification that can be of greater use to members within the specific discourse community. However, there are two major problems with using such a framework. First of all, in a corpus-based move analysis, researchers must first identify and tag the moves and move types in each individual text (Biber et al., 2007). This is a time-consuming and labor-intensive task and considering the relatively large sample of texts used in this study, would have been extremely difficult. Second, not all of the bundles found in the analysis can be easily classified 
Shahriari Ahmadi, H., Ghonsooly, B., \& Hosseini Fatemi, A.

according to moves and steps. Although texts of the same register exhibit similarities in terms of discourse objectives, there is a large degree of variation among them both in terms of content and linguistic characteristics. Therefore, to expect all bundles to neatly fit into a particular move or step category would be over-simplifying matters. As a result, the two frameworks of analysis used in this study are meant to have a complementary relationship with one another and provide better insight into the functions of lexical bundles through providing different perspectives.

During the classification process, the two raters were told to initially rely on their intuitions as highly proficient users of English, to determine whether a bundle served the purpose of any of the three major moves (establishing a territory, establishing a niche and presenting the present work). Following this step, the raters were required to validate their judgment by referring to the KWIC pertaining to the bundle in question. If more than one-third of the attestations contained the lexical bundle with a specific function, that bundle would be classified as fulfilling the observed move. For example, if 4 attestations out of 12 included a lexical bundle used to present the current study, it would be inferred that the lexical bundle was used to fulfill the third move in Swales' model. However, because the corpus was not coded for steps prior to the analysis, it was difficult to determine specifically which steps were being fulfilled by bundles in addition to specifying their move category. Some of the bundles were more easily classified relying on intuition, while others were more difficult and required the raters to read through the attestations carefully. For example, the bundle in the present study could easily be classified as presenting the present work (Move 3). On the other hand, the bundle is one of the cannot be easily classified without referring to context. However, by looking at the KWICs below, it becomes clear that this bundle is used to establish a territory for the readers.

accent is one of the first noticeable features of oral communication, (INNS Corpus)

Gender is one of the factors that can inherently be of interest to... (INNS Corpus)

vocabulary learning is one of the most problematic areas of language learning... (INNS Corpus)

self-confidence is one of the most important determinants in learner motivation... (INNS Corpus)

At the opposite end of the continuum, some bundles, such as the structure of the, seem to be obvious in their relation to a specific move (in this case Move 3); but once we look at the contexts in which these sequences occur, we soon realize that our intuitions have been misleading. In this case, the structure of the is not used to outline the structure of the paper. Rather, as in the case of many other bundles, it cannot be classified into any of the three move categories based on the sentences in which it occurs.

... understanding of the structure of the hypertext have fewer difficulties navigating ... (NS Corpus)

... a "fundamental relation" between "the structure of the body of knowledge of a given discipline and ... (NS Corpus)

Some bundles were seen to fulfill different functions at the same time. For instance, the sequence there has been $a$ was used both for establishing a territory (Move 1) and establishing a niche (Move 2). The first sentence below shows the use of this bundle for Move 1 and the second sentence demonstrates how the exact same bundle can be used in Move 2.

In recent years there has been a significant growth in the literature on the role of ... (NS Corpus)

Despite these recent studies, there has been a general lack of inquiry on how L2 writers perceive ...(NS Corpus)

Even more interesting are those bundles which relate to different moves, depending on the corpus they appear in. For example, the bundle it is important to serves to establish a territory (Move 1) in the INNS Corpus 
Analyzing research article introductions by Iranian and native English-speaking authors of Applied Linguistics and in the NS corpus, it is mainly used to establish a niche (Move 2). The examples below clearly show how this bundle is used by native and non-native writers to different ends.

It is important to point out that the only test which has followed this procedure to date is... (INNS Corpus)

... programs on ESL student academic achievement, it is important to study not only short-term student success rates ... (NS Corpus)

The analysis revealed that in the NS corpus, from the total number of identified lexical bundles (88), 52 could be classified according to the second analytical framework (59.09\%). As for the INNS corpus, 91 bundles (from 153) could be categorized based on Swales' model (59.47\%). In both corpora, the most number of bundles were used for the purposes of Move 1 (37 and 47 bundles in the NS and INNS corpora, respectively). Following Move 1 expressions, native speakers made greater use of bundles aimed at describing the niche (Move 2), with 10 bundles. However, non-native speakers were different in that they used Move 3 bundles (26) more commonly than Move 3 (18). Table 6 summarizes the different functional types of lexical bundles based on the second analytical framework.

\section{Table 7}

The number and percentage of different types of lexical bundles according to the second analytical framework

\begin{tabular}{lcccc}
\hline & NS - frequency & NS - Percentage & INNS - frequency & INNS - Percentage \\
\hline Move 1 Bundles & 37 & $71.15 \%$ & 47 & $51.60 \%$ \\
Move 2 Bundles & 10 & $19.23 \%$ & 18 & $19.78 \%$ \\
Move 3 Bundles & 7 & $13.46 \%$ & 26 & $28.57 \%$ \\
\hline
\end{tabular}

As can be seen in Table 6 , in both corpora, Move 1 bundles were more frequent than the other categories; but the percentages reveal that native speakers used a greater proportion of their lexical bundles to define the area of research. These bundles mostly include subject-specific bundles (e.g., as a second language, English for Academic Purposes) and intangible framing attributes (e.g., in the field of, the nature of the). Both groups of writers used almost the same rate of Move 2 bundles. Move 2 bundles were mostly of a verbal phrase (e.g., studies have been conducted, studies have focused on) and subordinate verbal phrase structure (e.g., the results showed that, it should be noted). Another characteristic of Move 2 bundles was that they were either referential expressions (the results of the, research in this area) or topic clarification discourse organizers (have been carried out, it is necessary to).

The difference in the total number of lexical bundles found within the two corpora and the fact that non-native writers in this study used more bundles corroborates the findings of other studies that have also reported greater use of lexical bundles by advanced EFL/ESL writers (Cortes, 2004; Hyland, 2008; Pang, 2009 and Wei and Lei, 2011). Different studies have attempted to investigate the reasons behind the advance non-native speakers' tendency to use lexical bundles more frequently and repetitively. Some of these studies have attributed this characteristic of non-native writing to the perception of prefabricated forms and patterns as reliable safety nets which can be used confidently, especially at times of uncertainty (De Cock, 2000; Granger, 1998). That is, the use of lexical bundles can be seen as a form of compensation strategy by non-native writers of English, trying to ensure the correctness and appropriateness of the language they use. In Granger's (1998) own words, non-native writers exhibit a tendency towards clinging on to "certain fixed phrases and expressions which [they] feel confident in using (p. 156).

The present study analyzed the identified lexical bundles according to two analytical frameworks. The main advantage of such an approach to the functional analysis of lexical bundles is that it provides a fresh perspective towards the categorization of these linguistic features, while retaining the previously-established taxonomy for comparative purposes. The first analysis found that referential bundles were the most common category in both 
corpora. This finding is in line with the general view that referential bundles are one of the most commonly found bundles in written academic registers. Biber and Baribieri (2007) analyzed four academic registers in their study and found that in three of the registers, referential bundles were the most common type. Also, in both groups stance expressions were not seen as frequently as other the other two functional categories. These stance expressions are mostly used as hedging devices, presenting the authors' assessment regarding the certainty of claims and propositions. The less frequent use of such bundles shows that as pointed out by previous researchers (Hyland, 1994; Lorenz, 1999), academic writing, especially L2 academic writing, shows more limited control on cautious language. However, the difference between the two groups of texts with regard to their proportional use of such bundles was not great, meaning that both groups generally made more limited use of stance bundles.

The syntactic classification of lexical bundles based on Biber et al.'s (1999) taxonomy showed that Iranian writers used considerably more verb phrase fragments and verb phrase elements followed by dependent clauses. Biber, Gray, and Ponpoon (2011) maintain that clausal subordination is more commonly encountered in academic conversation compared to academic writing, which generally tends to include more noun phrase constituents and complex phrasal structures. Considering these findings, Iranian EFL writers, in spite of their high level of language proficiency and academic writing expertise as specialists in the field of Applied Linguistics display a tendency towards writing in a conversational style, relying heavily on clausal elements and subordination. This outcome is not unexpected, because academic writing with its dependence on extended noun phrases and limited use of verbs is different from most other registers and can only be seen in academic writing, which aims to achieve greater brevity and a more density, conveying more information in fewer words.

\section{Conclusion}

This study investigated the use of 4-word lexical bundles in research article introductions by native English speakers and Iranian EFL writers in the field of Applied Linguistics. Through a corpus-based approach to linguistic analysis, the two groups of introductions were compared in terms of the number, type and function of lexical bundles. Results revealed that advanced writers tend to use more multi-word expressions in their writing. The lexical bundles were functionally categorized based on two frameworks of analysis. The results of the analysis according to the first framework showed greater conformity between the two groups of texts (Referential expressions were the most common type followed by discourse organizers and stance expressions). However, the results of the analysis based on the second analytical framework revealed that following the use of lexical bundles for establishing the area or realm of study (Move 1), non-native authors mostly used the second most number of bundles for referencing their research; while non-native writers used the second most number of bundles for establishing a niche.

Writing instructors can make use of the findings of this study by further emphasizing the role of lexical bundles for their students, explaining to them the various ways through which these prefabricated language patterns can be used to achieve moves and steps. This would consequently help them achieve writing that is more understandable to target readers and heightens their chances of publishing their work in accredited journals. Future studies can identify more lexical bundles used in different academic disciplines and construct an inventory of lexical bundles, used as genre frames. Such an inventory would most certainly be of great interest to academic writing instructors and advanced EFL writers alike.

The application of two different discourse frameworks in the functional analysis of lexical bundles in this study is also of interest. The fact that the results of one analysis led to the identification of differences between the two groups of texts, while results from the second analysis did not, shows that the selection of frameworks is of great methodological importance in lexical bundle studies. These frameworks are like lenses through which researchers can observe their subject of interest. Each of these lenses provides a different, yet equally noteworthy, view of the subject of analysis. That is, depending on what framework researchers choose for their investigations, they can expect different outcomes with different implications. For example, in this study, results from the first functional analysis showed that both groups of writers make infrequent use of stance expressions and hedging 
Analyzing research article introductions by Iranian and native English-speaking authors of Applied Linguistics devices. However, in the second analysis, we can see that native speakers use a larger percentage of their lexical bundles to introduce the realm of their study, compared to their non-native counterparts. One the other hand, non-native writers use a much greater percentage of their bundles to refer to their own study.

The results of this study also have implications for writing instructors in the field of English for Academic Purposes (EAP). According to frequency models of language learning, phraseological units are learned probabilistically and as a result of strengthening associations among co-occurring words (Ellis, 2002). The more frequently a learner is exposed to particular bundles, the higher the chances are for that learner to produce the bundles in speech or writing. This linear relationship between exposure and output is often times affected by L1 background. If a bundle shares an equivalent in the L1, the probability of its use will increase. As previously discussed, the proclivity towards extended noun phrase elements in the academic writing register is unnatural in that it is rarely seen in other registers. It is also very uncommon for other languages (in this case, Farsi) to follow such a trend; hence, learners, even those at advanced proficiency levels, find it counterintuitive and avoid using bundles representing noun phrase elements. As a result, it is recommended that EAP teachers and academic writing instructors create necessary awareness and improve the quality of academic writing by exposing learners to high-frequency phrasal bundles used by native speakers.

\section{References:}

Adel, A., \& Erman, B. (2012). Recurrent word combinations in academic writing by native and non-native speakers of English: A lexical bundle approach. English for Specific Purposes, 31, 81-92. $<$ http://dx.doi.org/10.1016/j.esp.2011.08.004>

Altenberg, B. (1998). On the phraseology of spoken English: the evidence of recurrent word combinations. In A. Cowie (Ed.), Phraseology: Theory, analysis and applications (pp.101-122). Oxford: Oxford University Press.

Butler, C. S. (1997). Repeated word combinations in spoken and written text: Some implications for Functional Grammar. In C. S. Butler, J. H. Connolly, R. A. Gatward, \& R. M. Vismans (Eds.), A fund of ideas: recent developments in functional grammar (pp. 60-77). Amsterdam: IFOTT, University of Amsterdam.

Biber, D., \& Baribieri, F. (2007). Lexical bundles in university spoken and written registers. English for Specific Purposes, 26(3), 263-286. <http://dx.doi.org/10.1016/j.esp.2006.08.003>

Biber, D., Gray, B., \& Ponpoon, K. (2011). Should we use characteristics of conversation to measure grammatical complexity in L2 writing development? TESOL Quarterly, 45(1), 5-35. $<$ http://dx.doi.org/10.5054/tq.2011.244483>

Biber, D., Connor, U., \& Upton, T. (2007). Discourse on the move: Using corpus analysis to describe discourse structure. Philadelphia: John Benjamins.

Biber, D., \& Conrad, S. (1999). Lexical bundles in conversation and academic prose. In H. Hasselgard \& S. Oksefjell (Eds.), Out of corpora: Studies in honor of Stig Johansson (pp. 181-189). Amsterdam: Rodopi.

Biber, D., Johansson, S., Leech, G., Conrad, S., \& Finegan, E. (1999). Longman grammar of spoken and written English. London: Longman.

Baker, P., \& Chen, Y. (2010). Lexical bundles in L1 and L2 academic writing. Language, learning and technology, 14(2), 30-49.

Cortes, V. (2004). Lexical bundles in published and student disciplinary writing: Examples from history and biology. English for Specific Purposes, 23, 397-423. <http://dx.doi.org/10.1016/j.esp.2003.12.001>

Cortes, V. (2002). Lexical bundles in published and student disciplinary writing: Examples from history and biology. English for Specific Purposes, 23(4), 397-423. <http://dx.doi.org/10.1016/j.esp.2003.12.001>

De Cock, S. (2000). Repetitive phrasal chunkiness and advanced EFL speech and writing. In C. Mair \& M. Hundt (Eds.), Corpus linguistics and linguistic theory (pp. 51-68). Amsterdam: Rodopi.

Diniz, L., \& Moran, K. (2005). Corpus-based tools for efficient writing instruction. Essential Teacher, 2(3), 36-39. 
Shahriari Ahmadi, H., Ghonsooly, B., \& Hosseini Fatemi, A.

Erman, B. (2009). Formulaic language from a learner perspective: What the learner needs to know. In B.

Corrigan, H. Quali, E. Moravcsik, \& K. Wheatley (Eds.), Formulaic language (pp. 27-50). Amsterdam: John Benjamins.

Flowerdew, L. (1996). Concordancing in language learning. In M. C. Pennington (Ed.), The power of CALL (pp. 97-114). Houston, TX: Athelstan.

Granger, S. (1998). Prefabricated patterns in advanced EFL writing: Collocations and formulae. In A. P. Cowie (Ed.), Phraseology: An interdisciplinary perspective (pp. 145-160). Amsterdam: John Benjamins.

Halliday, M. A. K. (1988). On the language of physical science. In M. Ghadessy (Ed.), Registers of written English (pp. 162-178). London: Pinter.

Howarth, P. (1998). Phraseology and second language proficiency. Applied Linguistics, 19(1), 24-44. $<$ http://dx.doi.org/10.1093/applin/19.1.24>

Hyland, K. (2008). Academic clusters: text patterning in published and postgraduate writing. International Journal of Applied Linguistics, 18, 41-62. <http://dx.doi.org/10.1111/j.1473-4192.2008.00178.x >

Leech, G. (1998). Preface. In S. Granger (ed.), Learner English on computer (pp. Xiv-xx). London: Longman.

Lewis, M. (2009). The idiom principle in L2 English: Assessing elusive formulaic sequences as indicators of idiomaticity, fluency, and proficiency. Saarbrucken, Germany: VDM Verlag.

Nation, I. S. P. (2001). Using small corpora to investigate learner needs: two vocabulary research tools. In M. Ghadessy, A. Henry and R. L. Roseberry (Eds.) Small corpus studies and ELT (pp. 31-45). Amsterdam: John Benjamins.

Pang, P. (2009). A study on the use of four-word lexical bundles in argumentative essays by Chinese English-majors: A comparative study based on WECCL and LOCNESS. Teaching English in China, 32, 25-45.

Swales, J. (2004). Research genres: Explorations and applications. Cambridge: CUP.

Tribble, C. (2002). Corpora and corpus analysis: New windows on academic writing. In J. Flowerdew (Ed.), Academic discourse (pp.131-149). London: Longman.

Wei, Y., \& Lei, L. (2011). Lexical bundles in the academic writing of advanced Chinese EFL learners. RELC Journal, 42(2), 155-166. <http://dx.doi.org/10.1177/0033688211407295> 